\title{
Prediction of dust storms in construction projects using intelligent artificial neural network technology
}

\author{
Salah Kh. Zamim', Noora Saad Faraj', Ibrahim A. Aidan ${ }^{3}$, Faiq M. S. Al-Zwainy ${ }^{4}$, \\ Mohammed A. AbdulQader ${ }^{5}$, Ibraheem A. Mohammed ${ }^{6}$ \\ ${ }^{1}$ Department of Civil Engineering, College of Engineering, Uruk University, Iraq \\ ${ }^{2,4}$ Department of Civil Engineering, College of Engineering, Al-Nahrain University, Iraq \\ ${ }^{3}$ Department of Civil Engineering, Al Maarif University College, Iraq \\ ${ }^{5,6}$ Department of Civil Engineering, College of Engineering, IsraUniversity, Jordan
}

\begin{abstract}
Sandstorms (dust storms) are considered the most events which cause destructive and costly damages in lots of desert regions. These sandstorms may be a reason of huge disasters or damages on environmental as well as health aspects. The aim of this paper is to develop a mathematical model for predicting the Dust Storm in Republic of Iraq using Artificial Neural Network (ANN) technique. As a case study, four construction projects in Iraqi cities were selected (Baghdad, Basrah, Samawa, and Nasiriya) in order to identifying and prediction of the sandstorms, which significantly help to reduce the effects of damages. Only one ANN model was built to predict a dust storm. The datas of this model cited from Iraqi Meteorological Organization and Seismology. Four factors were adapted to develop the model (Max. Temperature, Min. Temperature, Rain and Wind), It was found that ANN has the ability to predict the dust storm with a high accuracys off the correlation coefficient (R) which is $90.00 \%$, with a percentage of average accuracy is $89 \%$.
\end{abstract}

\begin{tabular}{l}
\hline Keywords: ANN, Traning, Testing, Validation, Predicting, Sandstorms, Iraq \\
Corresponding Author: \\
Faiq M. S. Al-Zwainy, \\
Department of Civil Engineering, College of Engineering, Al-Nahrain University, Iraq, \\
faiq.al-zwainy@eng.nahrainuniv.edu.iq
\end{tabular}

\section{Introduction}

One of the most natural events that happened frequently in most of the deserts regions in the world is the dust storms. That may be a reason of big disaster of properties and lead to death. Although, the sandstorms always take place at the waterless environments in the world, as in Mongolia, Middle East, Iraq, North China, Australia and Central Asia, the phenomenon of sandstorms has not yet been adequately explored, because of the lacks off observations surfaces, which are especially sparse in hyper-arid low populated desert regions. They are particularly scattered in low-arid, low-density desert areas.

Average temperature in Iraq ranges from $48^{\circ} \mathrm{C}$ or $118.4^{\circ} \mathrm{F}$, inn August and July, in order to belows zero in Januarys, greatest the rains happens between April and December, with means from 100 to180 mm per year. The mountainous area in the north of Iraq has a significantly higher rainfall than the central and southern regions. There are two types of wind, which the months of summer characterized, they are: south-east besides south-east, sandy, dry, winds, in which sometimes occasionally winds for each hour $80 \mathrm{Km}$., these sandstorms begin with April and continue to the early of June, then, begin with late Septembers to Novembers. That perhaps lasts for one days at the end and the beginning of the current term or for many other days.

These winds are often dusty, which may rise to several thousand meters. From mid-June to mid-September, prevailing winds are north (north and north-west).

The aim of most studies on sandstorms is to understand and characterized the phenomenon frequency, as well as the health and environment impact of it. In Central Asia presented a study about the sandstorms systems, 
which based on observation through a period of five years (1951-1955). As well as sandstorms frequency and durations of that time, so, synoptic pre-condition classifications for the sandstorm's onset and improved recommendationis for sandstorms forecasting are presented by Romanov in 1961 [1]. In Central Asia there are main distribution, seasonality and frequency characteristics of sandstorms which are represented [2]. There are other works about sandstorms forecasts [3], which have basically done on the base of the complicates models and images of satellites, or by techniques of artificial intelligence like "Artificial Neural Networks (ANNs)", which didn't have complete effectiveness [4][5].

This section reviews the literature related to dust storms with artificial intelligent techniques such as neural networks. Various researchers have used neural networks as a tool for prediction and optimization in different environmental project management areas are also reviewed, including dust storms as shown in Table 1.

The great majority of environmental project management neurals networks applicationss depended on the simple's backs propagations (BP) algorithms. One of the most important things that this study is based on previous studies, which was considered as scientific foundations. Research, exam, and analysis are the things which researcher begun with in previous studies, because the research processes are cumulative processes that depend on the previous ones [6].

Table 1. Historical studies

\begin{tabular}{|c|c|c|c|c|}
\hline No & Authors & Year & Type Research & Country \\
\hline Study 1 & Mei H., Peng, J., Shihuang Z. [7] & 2006 & Research Article & CHAINA \\
\hline Objective & \multicolumn{4}{|c|}{$\begin{array}{l}\text { The ANN approach was taken in order to model and forecast the happening of sandstorms, which dust storm } \\
\text { happening and daily mean meteorological measurements combinations are used in. The ANN model } \\
\text { performance in simulating sandstorm happenings has compared with a stepwise regression model. Between } \\
\text { the estimated sandstorm occurrences and observed there are coefficients of correlation, which taken from } \\
\text { the neural network procedure to be meaningfully more than these which found in the regression model with } \\
\text { the same input data. }\end{array}$} \\
\hline Tools & \multicolumn{4}{|c|}{ SPSS, ANN, RA } \\
\hline results & \multicolumn{4}{|c|}{$\begin{array}{l}\text { It is found that the regression model is worse than the ANN models performances with the same input data } \\
\text { for all studied sites, by compare them with the ANN model simulations of and the model of regression with } \\
\text { the observed dust records. The variables of meteorological have non-linear relationship with sandstorm } \\
\text { happening. }\end{array}$} \\
\hline No & Authors & Year & Type Research & Country \\
\hline Study 2 & $\begin{array}{l}\text { Weiwei L., Xiaoli W., Weizhou J., Guisheng Q., } \\
\text { Youzhi L. [8] }\end{array}$ & 2016 & Research Article & CHAINA \\
\hline Objective & \multicolumn{4}{|c|}{$\begin{array}{l}\text { Aims at the prediction of the dust removal effectiveness in rotating packed bed (RPB) in order to repaid it } \\
\text { develop. }\end{array}$} \\
\hline Tools & \multicolumn{4}{|c|}{$\begin{array}{l}\text { (CFBPNN), Feed-forward back propagation neural network (FFBPNN) then, Elman-orward back } \\
\text { propagation neural network (EFBPNN) }\end{array}$} \\
\hline
\end{tabular}

The main difference between the current study and the previous studies, is that current study derives a mathematical equation to predict the exact amount of dust during the implementation of the work activities in the work site in construction projects, while all previous studies did not have this feature, as it was limited to the application of smart neural networks only, without finding a mathematical equation. In addition, the present study is characterized by the used SNNS software for the application of artificial neural networks, which gives a strong addition to this study by conducting optimization during the construction of the neural network model.

This research results are very important for planners and academic researchers, as it represents a great addition and renewal of ideas in the field of project management, in addition to making neural networks and their applications a vital part in the lives of engineers in the areas of planning, organization and implementation, where this study provides very important information, providing an accurate formula for predict the amount of dust during construction projects. 
In order to solving lots of real-world problems powerful techniques are used which called as "Neural networks". They try to benefit from their experiences to develop the performance and to adjust themselves to make some changes in the environments. As well as, it may be deals with information are not completed or noisy data, also it can be more effectively in states whereas it may be not able to define the steps or the rules, which can solve the problem [9][10].

The main components are shown in Figure 1 are created an artificial neuron. So, the elements are valid if the neurons are used for output, input or are in ones off the hiddens layerss. These are: output functions, activation function, summation function (competition), and weighting factors, then error functions and the value of backpropagated [11][12].

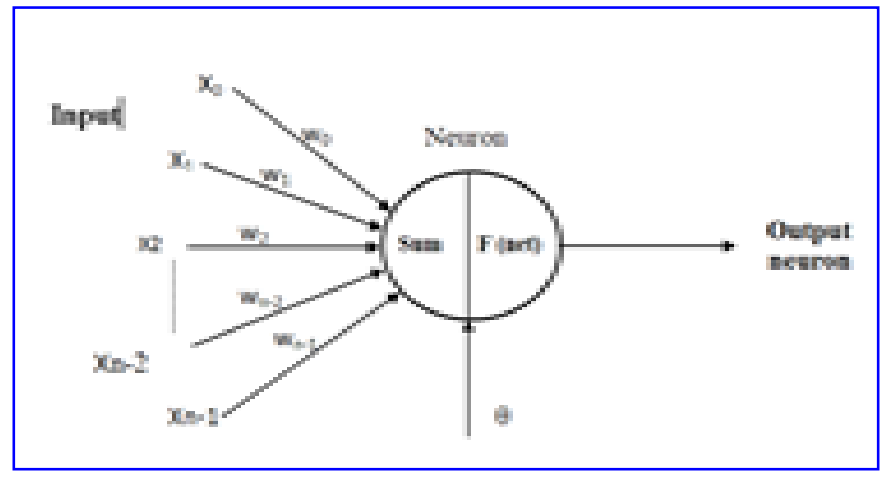

Figure 1. Artificial neuron [13]

\section{Justifications of the research}

This research is depended on the following reasons:

1) Iraqi Meteorological Organization and Seismology has real demand toward the creation of efficient management technique to predict dust storms.

2) Help estimator in predicting the dust storms.

\section{Research aims}

The main objectives of this study are:

1) Identifying the factors affecting on the dust storms.

2) Developing an artificial mathematical model for predicating the dust storms using ANN technique.

3) Evaluating the performance of the ANN model through validity of the developed model.

\section{Development of ANN model for predicating the dust storms}

\subsection{Factor affecting on dust storms}

One of the most important tasks of this objective is to determine which variables are considered as important indicators. Once the appropriate variables have been determined, the dust storms estimation can be performed using ANN.

This study describes the development of ANN model to predicating the dust storms based on recent historical data. The data used to develop the ANN model were collected by Iraqi Meteorological Organization and Seismology. The model input consists of four variables (F1, F2, F3, and F4) as shown in Table 2. Wihle Table 3 showing the splitsthe data into three stes, $70 \%$ as a training, $15 \%$ as a testingsand $15 \%$ as a validation. 
Table 2. Affecting Variable's on Dust Storms

\begin{tabular}{|c||l||c||c||}
\hline Variables & \multicolumn{1}{|c||}{ Description } & Max & Min \\
\hline \hline $\mathrm{F}_{1}$ & Maximum Temperature & $48.8^{\circ} \mathrm{c}$ & $16^{\circ} \mathrm{c}$ \\
\hline \hline $\mathrm{F}_{2}$ & Minimum Temperature & $32.8^{\circ} \mathrm{c}$ & $3.8^{\circ} \mathrm{c}$ \\
\hline \hline $\mathrm{F}_{3}$ & $\begin{array}{l}\text { Rain: The cyclone rains are due to the } \\
\text { convergence of different winds in the temperature } \\
\text { and humidity. }\end{array}$ & $30 \mathrm{~mm}$ & $8 \mathrm{~mm}$ \\
\hline \hline $\mathrm{F}_{4}$ & $\begin{array}{l}\text { Wind: A change in the ratio of the velocity of } \\
\text { atmospheric gases }\end{array}$ & $40 \mathrm{knots}$ & $0.3 \mathrm{knot}$ \\
\hline
\end{tabular}

Table 3. Showing the effects of data division on performance of ANN sandstorms model

\begin{tabular}{|c||c||c|}
\hline Training \% & Testing \% & Validation \% \\
\hline \hline 70 & 15 & 15 \\
\hline
\end{tabular}

\subsection{Trnsfer function selection of ANN model}

In this step transfer function was selected. The sigmoidal activation function selected in those models have the lowest roots means squares errors equal to $(0.45)$, as shown in Table 4, it's supposed that transfer function considers more optimum. Therefore, it's selected in these models.

Table 4. Showing the impacts of selected transfer function on ANN model performance

\begin{tabular}{|c||c||c||c||}
\hline The Kinds of Transfer Function & MAE & RMSR & Correlation of Coefficient (r)\% \\
\hline \hline Hard limiting activation function & 0.45 & 0.55 & $89 \%$ \\
\hline \hline Sigmoidal activation & 0.36 & 0.45 & $92 \%$ \\
\hline \hline Piecewise-Linear function & 0.51 & 0.58 & $84 \%$ \\
\hline
\end{tabular}

\subsection{Parameter of learning rate selection of ANN model}

Table 5 clarifies that the impact of the parameter learning rate on ANN Model, whereas the best value parameter learning rate equal to 0.2 then achieved the maximum coefficient of correlation is (92\%). Therefore, that was used in this model.

Table 5. Showing the impact of change the parameter learning rate on ANN model performance

\begin{tabular}{|c||c||c||c||}
\hline Parameter Learning Rate & MAEs & RMSEs & Coefficient of Correlation \\
\hline \hline 0.1 & 0.36 & 0.65 & $92 \%$ \\
\hline \hline 0.2 & 0.36 & 0.55 & $92 \%$ \\
\hline
\end{tabular}




\begin{tabular}{|c||c|c|c||}
\hline Parameter Learning Rate & MAEs & RMSEs & Coefficient of Correlation \\
\hline \hline 0.3 & 0.39 & 0.66 & $85 \%$ \\
\hline 0.4 & 0.40 & 0.67 & $86 \%$ \\
\hline 0.5 & 0.41 & 0.68 & $86 \%$ \\
\hline 0.6 & 0.42 & 0.69 & $86 \%$ \\
\hline 0.7 & 0.43 & 0.70 & $85 \%$ \\
\hline 0.8 & 0.45 & 0.71 & $85 \%$ \\
\hline 0.9 & 0.47 & 0.72 & $88 \%$ \\
\hline \hline
\end{tabular}

\subsection{Parameter of momentum term of ANN model}

Table 6 shows the impact of the parameter momentum term on ANN model, whereas the greatest value parameter momentum term equal to 0.8 and achieved the highest correlation coefficient (92\%), hence it was used in this model. Also, it has the mean significance, which is error absolutely (0.36) in addition significant lowest value of roots means squares errors equal to (0.55), then the maximum of correlation coefficient ( $r)$ is $(92 \%)$, therefore it's used in that model .

Table 6: Showing the impact of change the parameter momentum term on ANN model performance

\begin{tabular}{|c||c||c|c|}
\hline Parameter Momentum Term & MAE & RMSE & Coefficient of Correlation \\
\hline \hline 0.20 & 0.40 & 0.64 & $84 \%$ \\
\hline 0.30 & 0.41 & 0.64 & $84 \%$ \\
\hline 0.35 & 0.41 & 0.63 & $85 \%$ \\
\hline 0.40 & 0.40 & 0.62 & $86 \%$ \\
\hline 0.45 & 0.40 & 0.62 & $86 \%$ \\
\hline 0.5 & 0.39 & 0.61 & $87 \%$ \\
\hline \hline 0.55 & 0.39 & 0.60 & $88 \%$ \\
\hline \hline 0.6 & 0.38 & 0.59 & $89 \%$ \\
\hline \hline 0.65 & 0.38 & 0.59 & $90 \%$ \\
\hline \hline 0.7 & 0.37 & 0.58 & $90 \%$ \\
\hline \hline 0.75 & 0.37 & 0.58 & $92 \%$ \\
\hline \hline 0.8 & 0.36 & 0.55 & $91 \%$ \\
\hline \hline 0.9 & 0.37 & 0.55 & $91 \%$ \\
\hline \hline 0.95 & 0.36 & 0.56 & \\
\hline \hline
\end{tabular}




\subsection{Model Equation}

The connecting weights which have clarified in Table 7 gained from SNNS software for the optimum ANN Model. Neural network simulator at first advanced at University of Stuttgart, which is known as "SNNS (Stuttgart Neural Network Simulator)".

Table 7. Weights for the ANN model optimal

\begin{tabular}{|c||c||c||c||c||}
\hline Factors & $\mathbf{F}_{\mathbf{1}}$ & $\mathbf{F}_{\mathbf{2}}$ & $\mathbf{F}_{\mathbf{3}}$ & $\mathbf{F}_{\mathbf{4}}$ \\
\hline \hline Weights & 0.156 & 0.057 & 0.1 & 0.19 \\
\hline
\end{tabular}

The report of SNNS software provided the value of $(\theta 1)$ which is the weight from node in the hidden layer to node in the output layer. The value of $(\theta 1)$ was found to be (5.01). Based on values of weight of inputs and outputs obtained from the run of the support vector machines, predicted dust storms can be calculated as follows:

Sandstorms $=\left[\left\{5.01+\left(0.156 * \mathrm{~F}_{1}\right)+\left(0.057 * \mathrm{~F}_{2}\right)+\left(0.1 * \mathrm{~F}_{3}\right)+\left(0.19 * \mathrm{~F}_{4}\right)\right\} * 0.155+20.55\right]$

\subsection{Model Validity}

Table (8) illustrates the contrastive study results. The Main Abslut Persentage Error (MAPE) and Averages Accuracy Percentage (AAP) generated by ANN Model were found to be (10\%) and (90\%) respectively. Consequently, it can be determined that the ANN Model has excellent agreement with the actual value.

Table 8. The ANN model results

\begin{tabular}{|c||c|}
\hline Description & Results \\
\hline \hline MAPE & $10 \%$ \\
\hline \hline AAP\% & $90 \%$ \\
\hline \hline R & $92 \%$ \\
\hline \hline $\mathrm{R}^{2}$ & $84 \%$ \\
\hline
\end{tabular}

The error category in that model was created in MAPE. Table 8 letting to this tab; MAPE of ANN Model was excellent. Therefore, high predication accuracy wants more time in order to training the network and exam for complexity ANN model .

To determine the ANN model validity, the values of prediction are planned in contradiction of the actualvalues for a validation data set. Figure 2 showing that the abilities of ANN Model. Throughout Figure 2, it may be saw that the $\mathrm{R}^{2}$ equal (84\%) for ten of past period. 


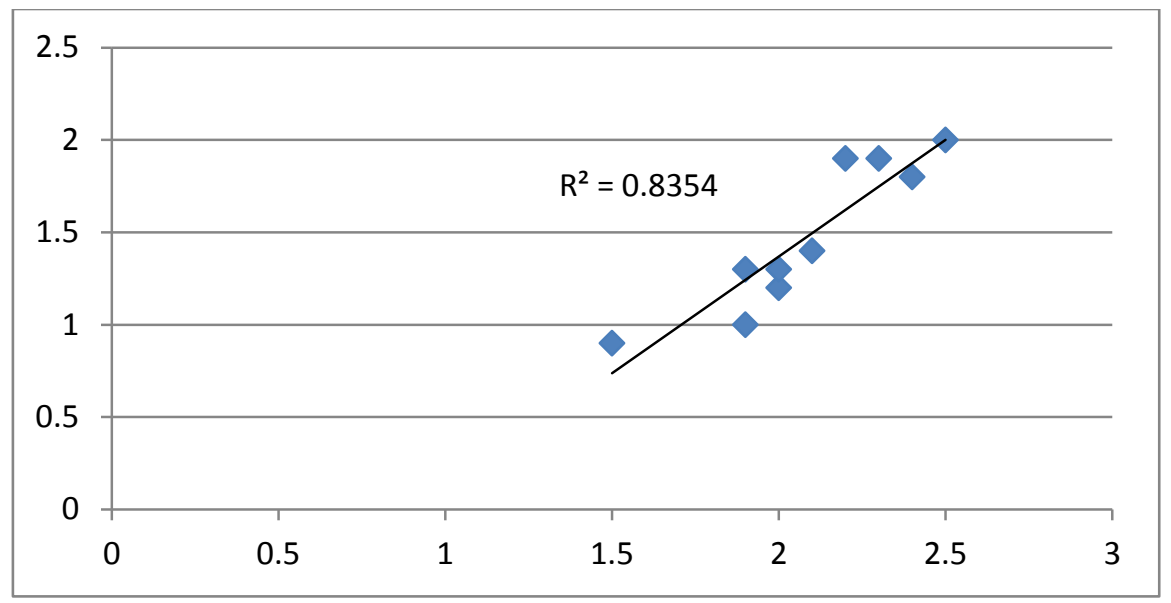

Figure 2. The Comparison of predicting and observing value for validation data

\section{Conclusions}

The most important conclusions of this study are as follows:

1) ANN can be considered as a useful tool typically, when only a limited or incomplete data set is available for cost analysis.

2) One ANN model can be able to study the causes-effects relationships between output and input, in the training stage, four factors are adopted to developed model (Maximum. Temperature, Minimum Temperature, Rain and Wind) the results showed Average Accuracy percentage (AAP) of $90 \%$ and the coefficient of correlation (R) was $92.0 \%$.

\section{The availability of data}

The study findings, which are supported by the data, are obtainable by the corresponding writer upon request.

\section{Interest conflicts}

The writers affirmed that they had not interest conflicts.

\section{Acknowledgment}

I'd like to thank those respected persons who have helped and guided us to achieve this paper; they really deserve all respect and gratitude. Then, we'd like to thank all the staff of Al-Nahrain University to help us to get guideline for our paper by providing us lots of consultations. As well as, we also want to thank and give our gratitude to everyone who has guided or advised us in submitting or writing this paper.

\section{References}

[1] B. S. Babu, A. Suneetha, G. C. Babu, Y. J. N. Kumar, G. Karuna, and G. W. Optimization, "Medical Disease Prediction using Grey Wolf optimization and Auto Encoder based Recurrent Neural Network," Period. Eng. Nat. Sci., vol. 6, no. 1, pp. 229-240, 2018.

[2] A. S. Abdullah, M. A. Abed, and I. Al Barazanchi, "Improving face recognition by elman neural network using curvelet transform and HSI color space," Period. Eng. Nat. Sci., vol. 7, no. 2, pp. 430-437, 2019. 
[3] B. H. Barnum, N. S. Winstead, J. Wesely, A. Hakola, P. R. Colarco, O. B. Toon, P. Ginoux, G. Brooks, L. Hasselbarth, and B. Toth, "Forecasting Dust Storms using the CARMA-Dust Model and MM5 Weather Data". Journal of Environmental Modelling \& Software, vol. 19, no. 1, p. 129-140, 2004.

[4] M. Huang, G. Peng, J. Zhang, and S. Zhang, "Application of Artificial Neural Networks to the Prediction of Dust Storms in Northwest China". Journal of Global and Planetary Change, VOL. 52, no.1, P. 216224, 2006.

[5] Z. Lu, Q. Zhang, and Z. Zhao, 2006, "SVM in the Sand-Dust Storm Forecasting". Proceedings of the Fifth International Conference on Machine Learning and Cybernetics, Dalian, 13-16 August, 2006.

[6] F. M. S. Al-Zwainy, "The Use of Artificial Neural Network for Estimating Total Cost of Highway Construction Projects", a thesis submitted to the Civil Engineering Department, College of Engineering, Baghdad University, Ph.D. Iraq, 2009.

[7] H. Mei, P. Gongbing, Z. Jiashen, Z. Shihuang, "Application of artificial neural networks to the prediction of dust Storms in Northwest China". Global and Planetary Change, vol. 52, no.1, p. 216-224, 2006.

[8] L. Weiwei, W. Xiaoli, J. Weizhou, Q. Guisheng, L. Youzhi, "Modelling of Dust Removal in Rotating Packed Bed Using Artificial Neural Networks (ANN) ", 2016.

[9] F. M. S. Al-Zwainy, R. H. Al-Suhaily, Z. M. Saco, Project Management and Artificial Neural Networks: Fundamental and Application, LAP LAMBERT Academic Publishing, Jermany, 2015.

[10] F. M. S. Al-Zwainy, "The Use of Artificial Neural Networks for Productivity Estimation of finish Works for Building Projects", Journal of Engineering and Development, vol. 16, no. 2, p. 42-60, 2012.

[11] T. Tharmalingam, V. Vijayakumar, "An Efficient Convolutional Neural Network Based Classifier to Predict Tamil Writer", Periodicals of Engineering and Natural Sciences, vol. 6, no. 1, p. 285-295.

[12] S. Serin, S. Karahancer, E. Eriskin, N. Morova, M. Saltan, S. Terzi, "Estimation of Specific Gravity with Penetration and Penetration Index Parameters by Artificial Neural Network", Journal of Engineering and Development, vol. 5, no. 2, p. 161-164, 2017.

[13] K. A.Zidan, S.S.Jumaa, , "Finger Vein Recognition using Two Parallel Enhancement Approachs based Fuzzy Histogram Equalization", Journal of Engineering and Development, vol. 7, no. 1, p. 514-529, 2019. 